\title{
IDENTIFIKASI DAN PENENTUAN KADAR SIKLAMAT PADA SIRUP TRADISIONAL ACEH YANG DIJUAL DI KOTA LHOKSEUMAWE
}

\author{
Al-Muqsith ${ }^{1}$, Cut Sidrah Nadira ${ }^{2}$ \\ ${ }^{1}$ Bagian Anatomi, Fakultas Kedokteran, Universitas Malikussaleh, Lhokseumawe, Indonesia \\ ${ }^{2}$ Bagian Fisiologi, Fakultas Kedokteran, Universitas Malikussaleh, Lhokseumawe, Indonesia
}

Email: sidrahnadira@gmail.com

\begin{abstract}
Abstrak
Kebiasaan mengkonsumsi jajanan seperti minuman sirup yang diproduksi dari industri rumah tangga sudah menjadi kebiasaan umum yang ditemui di berbagai tingkat sosial ekonomi masyarakat di wilayah Indonesia. Pembuatan minuman sirup tersebut masih didapati memakai bahan kimia tambahan berupa pemanis buatan seperti siklamat. Penggunaan siklamat perlu diwaspadai karena dalam jumlah berlebihan akan menimbulkan efek samping yang merugikan kesehatan. Penelitian ini bertujuan untuk mengetahui kadar siklamat dalam sirup tradisional Aceh yang dijual di kota Lhokseumawe. Penelitian ini menggunakan metode deskriptif secara kualitatif dan kuantitatif. Identifikasi ada tidaknya kandungan siklamat di dalam sirup secara kualitatif menggunakan metode uji pengendapan dan uji kromatografi lapis tipis (KLT), sedangkan penetapan kadar siklamat ditentukan secara kuantitatif menggunakan spektrofotometri UV. Hasil Penelitian menunjukkan bahwa sebanyak 7 sampel sirup tradisional aceh yang diuji, semuanya positif mengandung natrium siklamat, dengan kadar siklamat tertinggi pada sampel E yaitu $25,54165 \mathrm{mg} / \mathrm{kg}$ dan terendah pada sampel D yaitu $6,38095 \mathrm{mg} / \mathrm{kg}$. Kesimpulan yang didapat bahwa kadar natrium siklamat sebagai pemanis tambahan yang didapat pada seluruh sampel sirup masih sesuai dengan peraturan yang ditetapkan oleh BPOM tahun 2019 yaitu $250-350 \mathrm{mg} / \mathrm{kg}$.
\end{abstract}

Kata kunci: siklamat; sirup; spektrofotometri UV; uji KLT ; uji pengendapan

Identification and determination of levels cyclamate In aceh traditional syrup for sale In the city of lhokseumawe

\begin{abstract}
Consuming beverages such as syrups produced from home industries has become a common habit found at various socio-economic levels of society in Indonesia. These syrup is still found to use additional chemicals such as cyclamate as artificial sweeteners. The use of cyclamate needs to be vigilant because of the detrimental effects to health occurs when excessive amounts are consumed. This study aims to determine the levels of cyclamate in traditional Aceh syrup that being sold in Lhokseumawe. This research uses descriptive qualitative and quantitative methods. Identification of the cyclamate content in the syrup qualitatively using the precipitation test and thin layer chromatography test (TLC), while the cyclamate level was determined quantitatively using UV spectrophotometry. The results showed that all of 7 samples of traditional Aceh syrup tested were positive for sodium cyclamate, with the highest cyclamate level in sample E, $25.54165 \mathrm{mg} / \mathrm{kg}$ and the lowest in sample D, $6.38095 \mathrm{mg} / \mathrm{kg}$. The conclusion was that the levels of sodium cyclamate as an
\end{abstract}


additional sweetener obtained in all syrup samples were accordance to the regulations set by BPOM in 2019, as much as $250-350 \mathrm{mg} / \mathrm{kg}$.

Keywords: Cyclamate; Deposition test; syrup; TLC test; UV spectrophotometry

\section{PENDAHULUAN}

Saat ini banyak sekali ditemukan makanan dan minuman yang tidak memenuhi persyaratan dan mengandung bahan berbahaya seperti penambahan pemanis buatan oleh produsen sebagai pengganti gula, khususnya yang dijual di sekitar sekolah. Hal tersebut dikarenakan biaya yang diperlukan untuk mendapatkan pemanis buatan ini tidak terlalu besar, harga pemanis buatan lebih murah dibandingkan dengan pemanis gula asli. ${ }^{1}$

Minuman yang diproduksi dari Industri rumah tangga dan yang diedarkan di wilayah Indonesia masih didapati memakai bahan kimia tambahan dan tidak higienis, terutama yang dijual untuk anak di sekolah. Hal ini tentunya dapat membahayakan kesehatan anak sekolah. ${ }^{2}$ Survei yang dilakukan oleh Badan Pengawasan Obat dan Makanan (BPOM) tahun 2004 di sekolah dasar (seluruh Indonesia) menunjukkan bahwa dari sekitar 550 jenis makanan dan minuman yang diambil untuk sampel pengujian didapati $60 \%$ jajanan anak sekolah tidak memenuhi standar mutu dan keamanan. ${ }^{3}$

Jenis pemanis buatan sangat bermacam-macam antara lain sakarin, siklamat, aspartam, dulsin, dan sorbitol sintesis. Namun tidak semua pemanis buatan diperbolehkan penggunaannya di Indonesia. ${ }^{4}$ Penggunaan pemanis buatan perlu diwaspadai karena dalam jumlah berlebihan akan menimbulkan efek samping yang merugikan kesehatan. ${ }^{5}$ Pemberian siklamat secara oral selama 24 hari pada mencit dalam dosis $1,1 \mathrm{mg}$ dan $1,65 \mathrm{mg} / \mathrm{KgBB}$ dapat menghentikan produksi sel parenkim paru (Habisukan, 2018, p.82). Mencit yang diberi pemanis buatan peroral dalam dosis $5 \mathrm{mg} / \mathrm{KgBB}$ menunjukkan perubahan hepar dengan skor I (berubah 0,52\% - 0,56\%). Namun, pemberian pemanis buatan dalam dosis $15 \mathrm{mg} / \mathrm{KgBB}$ selama 30 hari dapat menyebabkan perubahan degenerasi dan nekrosis sel hepar dengan skor 3 sebesar $35,72 \%{ }^{6}$

Siklamat merupakan jenis pemanis buatan yang cukup sering digunakan karena memiliki tingkat kemanisan 30 kali lebih manis dibanding gula dengan jumlah kemanisannya yaitu 3,94 kkal/g dan tidak menimbulkan aftertaste. Hasil metabolisme siklamat yaitu sikloheksamina dan bersifat karsinogenik, sehingga sekresi lewat urine dapat merangsang pertumbuhan tumor kandung kemih. ${ }^{7}$ World Health Organization (WHO) menyatakan 
adanya batas maksimum kadar siklamat yang boleh dikonsumsi perhari atau Acceptable Daily Intake (ADI) yakni $11 \mathrm{mg} / \mathrm{kg} \mathrm{BB}{ }^{8}$

Menurut Permenkes No.722/MENKES/PER/IX/1988 tentang BTP minuman yang diperbolehkan untuk siklamat adalah 0,3 gram atau $300 \mathrm{mg}$. Menurut BBPOM No.11 Tahun 2019 batas maksimum BTP Pemanis buatan jenis siklamat adalah 250-350 mg. Siklamat telah dilarang penggunaannya di beberapa negara pada tahun 1970-an, yaitu di Amerika, Kanada dan Inggris karena produk degredasinya bersifat karsinogenik. Penggunaan siklamat ini tidak dilarang di Indonesia, namun pemerintah telah menetapkan batas maksimum yang diperbolehkan. ${ }^{9}$

Menurut Sudjadi (2012), secara umum analisis bahan pemanis sintetis jenis siklamat yang terdapat dalam minuman secara kualitatif dapat dilakukan dengan cara uji pengendapan seperti yang tertera dalam Standar Nasional Indonesia (SNI) No. 01-2893 tahun 1992. Terbentuknya endapan kristal putih dari reaksi antara $\mathrm{BaCl}_{2} 10 \%$ berfungsi untuk mengendapkan pengotor-pengotor yang ada dalam larutan, seperti adanya ikatan ion karbonat dengan $\mathrm{NaNO}_{2}$ 10\% berfungsi untuk memutuskan ikatan sulfat dalam siklamat. Ketika ikatan sulfat telah diputus maka ion $\mathrm{Ba}^{2+}$ akan bereaksi dengan ion sulfat dan menghasilkan endapan barium sulfat $\left(\mathrm{BaSO}_{4}\right)$ dalam suasana asam kuat menunjukan adanya asam siklamat, adapun fungsi dari pemanasan untuk menguapkan reaksi dari larutan $\mathrm{HCl} 10 \%$, larutan $\mathrm{BaCl}_{2} 10 \%$ dan $\mathrm{NaNO}_{2} 10 \%{ }^{10}$

Spektrofotometri - Analisis kuantitatif siklamat dilakukan dengan metode spektrofotometri. Spektrofotometri adalah alat yang digunakan untuk mengukur adsorben atau transmiten suatu zat tertentu. Zat ini biasanya ada dalam larutan dan waktu dilakukan pengukuran absorbansi zat pelarut tidak terukur. Pembuatan larutan blanko harus dilakukan guna membandingkan absorpsi oleh pelarut murni serta absorpsi oleh larutan sampel. Spektrofotometri harus diatur sedemikian rupa sehingga transmiten larutan blanko 100\%. ${ }^{11}$ Spektrofotometri sesuai dengan namanya adalah alat yang terdiri atas spektrofotometer dan fotometer. Spektrofotometer menghasilkan sinar dari spektrum dengan panjang gelombang tertentu dan fotometer adalah alat pengukur intensitas cahaya yang ditransmisikan atau yang diabsorbsi. Spektrofotometer tersusun dari sumber spektrum tampak yang kontinyu, monokromator, sel pengabsorbsi dan alat pengukur perbedaan absorbsi antara sampel dan blanko ataupun pembanding. ${ }^{12}$

\section{METODE}

Penelitian ini merupakan penelitian deskriptif dengan teknik total sampling. Sampel sirup tradisional Aceh yang dijual di pasar Kota Lhokseumawe yang telah memenuhi kriteria 
inklusi dan eksklusi sebanyak 7 sampel. Variabel penelitian meliputi: Variabel bebas meliputi sirup tradisional Aceh, Variabel terikat berupa ada tidaknya kandungan siklamat dan jumlah kadar siklamat di sirup tradisional Aceh. Data yang diperoleh dari hasil penelitian di laboratorium selanjutnya akan diolah secara manual dan dianalisis secara deskriptif dalam bentuk tabel dan grafik.

\section{HASIL}

Analisis kualitatif dilakukan pada sampel untuk menunjukkan ada atau tidaknya senyawa pemanis buatan, natrium siklamat pada sampel.

Tabel 1. Hasil Analisis Kualitatif Natrium Siklamat Metode Pengendapan

\begin{tabular}{cccc}
\hline No & Sampel & Hasil pengamatan & Kesimpulan \\
\hline 1 & A & endapan putih & Positif(+) \\
2 & B & endapan putih & Positif(+) \\
3 & C & endapan putih & Positif(+) \\
4 & D & endapan putih & Positif(+) \\
5 & E & endapan putih & Positif(+) \\
& & & Positif(+) \\
6 & F & endapan putih & Positif(+) \\
\hline 7 & G & endapan putih & \\
\hline
\end{tabular}

Berdasarkan Tabel 1 di atas, diketahui bahwa dari 7 sampel Sirup tradisional aceh yang diuji semuanya positif mengandung natrium siklamat yang ditandai dengan terbentuknya endapan putih.

Tabel 2. Hasil Analisis Kualitatif Natrium Siklamat Secara KLT

\begin{tabular}{cccccc}
\hline No & Sampel & $\begin{array}{c}\text { Jarak } \\
\text { Pengembang } \\
\text { (cm) }\end{array}$ & $\begin{array}{c}\text { Jarak } \\
\text { Rambat } \\
\text { (cm) }\end{array}$ & Rf & Keterangan \\
\hline & Pembanding & 12 & 4,7 & 0,39 & Bercak Putih (+) \\
1 & A & 12 & 4,2 & 0,35 & Bercak Putih (-) \\
2 & B & 12 & 4,3 & 0,358 & Bercak Putih (-) \\
3 & C & 12 & 4,6 & 0,38 & Bercak Putih (+) \\
4 & D & 12 & 4,1 & 0,34 & Bercak Putih (-) \\
5 & E & 12 & 4,5 & 0,375 & Bercak Putih (+) \\
6 & F & 12 & 4 & 0,33 & Bercak Putih (-) \\
7 & G & 12 & 4,8 & 0,4 & Bercak Putih (+) \\
\hline
\end{tabular}


Metode analisis kualitatif yang lain yaitu metode Kromatografi Lapis Tipis (KLT) juga dilakukan sebagai uji penegasan pada sampel yang sudah positif di uji kualitatif secara pengendapan sebelumnya. Tabel 2 di atas, memperlihatkan bahwa dari 7 sampel yang diuji diantaranya 3 sampel positif mengandung natrium siklamat yang ditandai dengan terbentuknya bercak putih dan nilai Rf yang memenuhi standar pada sampel C, E, G. Hasil yang didapat dari plat semua sampel menimbulkan bercak putih namun yang mendekati nilai Rf dengan pembanding yaitu sampel C, E dan G.

Dari 7 sampel yang positif metode pengendapan dan 3 sampel yang positif metode KLT, sampel tersebut diukur kadar natrium siklamatnya menggunakan metode spektrofotometri UV pada panjang gelombang maksimum siklamat yaitu $314 \mathrm{~nm}$ dengan mengukur absorbansinya, selanjutnya konsentrasi siklamat dalam sampel dapat dihitung dengan menggunakan kurva kalibrasi dengan persamaan regresi $\mathrm{y}=\mathrm{a} \pm \mathrm{bx}$. Kadar siklamat

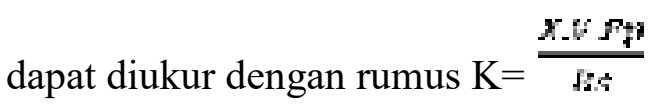

Tabel 3 Hasil Analisis Natrium Siklamat pada Sampel

\begin{tabular}{|c|c|c|c|c|c|}
\hline $\begin{array}{l}\text { Sampel } \\
\text {. }\end{array}$ & $\begin{array}{l}\text { Volume } \\
\text { (mL) }\end{array}$ & Absorbansi & Rata2 & $\begin{array}{l}\text { Konsentrasi } \\
(\mu \mathrm{g} / \mathrm{ml})\end{array}$ & $\begin{array}{r}\text { Kadar } \\
(\mathrm{mg} / \mathrm{kg})\end{array}$ \\
\hline \multirow[t]{2}{*}{ A } & 50 & 0,4759 & 0,4804 & 32,3016 & 16,1508 \\
\hline & 50 & 0,4849 & & & \\
\hline \multirow[t]{2}{*}{ B } & 50 & 0,4181 & 0,4144 & 27,0649 & 13,53245 \\
\hline & 50 & 0,4107 & & & \\
\hline \multirow[t]{2}{*}{$\mathrm{C}$} & 50 & 0,4486 & 0,41735 & 27,2976 & 13,6488 \\
\hline & 50 & 0,3861 & & & \\
\hline \multirow[t]{2}{*}{$\mathrm{D}$} & 50 & 0,2252 & 0,2342 & 12,7619 & 6,38095 \\
\hline & 50 & 0,2432 & & & \\
\hline \multirow[t]{2}{*}{$\mathrm{E}$} & 50 & 0,7052 & 0,71705 & 51,0833 & 25,54165 \\
\hline & 50 & 0,7289 & & & \\
\hline \multirow[t]{2}{*}{$\mathrm{F}$} & 50 & 0,4332 & 0,43635 & 28,8056 & 14,4028 \\
\hline & 50 & 0,4395 & & & \\
\hline \multirow[t]{2}{*}{ G } & 50 & 0,6014 & 0,54945 & 37,7817 & 18,89085 \\
\hline & 50 & 0,4975 & & & \\
\hline
\end{tabular}


Dari Hasil Tabel diatas menunjukkan kadar siklamat tertinggi pada sampel E yaitu $25,54165 \mathrm{mg} / \mathrm{kg}$ dan terendah pada sampel D 6,38095 mg/kg.

\section{PEMBAHASAN}

Pada pengujian kualitatif secara pengendapan, natrium siklamat bereaksi dengan asam klorida menghasilkan amin alifatis primer (sikloheksamina), asam sulfat, dan natrium klorida. Asam sulfat yang terbentuk bereaksi dengan barium klorida membentuk endapan barium sulfat yang tersuspensi dalam campuran. Penambahan $\mathrm{HCl} 10 \%$ berfungsi untuk mengasamkan larutan. Larutan dibuat dalam keadaan asam agar reaksi yang akan terjadi dapat lebih mudah bereaksi. Penambahan $\mathrm{BaCl}_{2} \quad 10 \%$ bertujuan untukmengendapkan pengotor-pengotor yang ada dalam larutan, seperti adanya ion karbonat. Dan penambahan $\mathrm{NaNO}_{2} 10 \%$ berfungsi untuk memutuskan ikatan sulfat dalam siklamat. Ketika ikatan sulfat telah diputus maka ion akan bereaksi dengan ion sulfat dan menghasilkan endapan barium sulfat $\left(\mathrm{BaSO}_{4}\right)$ endapan putih. ${ }^{13}$ Pada pengujian ini didapatkan hasil dari 7 sampel yang diuji semuanya positif mengandung siklamat.

Pada penelitian ini menggunakan uji pendugaan dengan metode pengendapan kemudian dilanjutkan dengan uji penegasan dengan metode KLT menggunakan fase gerak aseton : ammonia (90:10). Pada uji penegasan ini sampel diasamkan dengan asam sulfat 10\% kemudian diekstraksi dengan etil asetat dalam corong pisah dan lapisan air serta etil asetat disaring dengan melalui Na2SO4 anhidrat untuk menghilangkan air. Hasil ekstraksi etil asetat tersebut diuapkan di atas penangas air sehingga etil asetat tersisa $2 \mathrm{~mL}$. Selanjutnya ditotolkan masing-masing sampel pada plat KLT sebanyak $2 \mu \mathrm{L}$ dengan jarak 1,5 cm dari tepi lempeng, kemudian plat dimasukkan ke dalam chamber yang telah dijenuhkan dengan fase gerak aseton : ammonia (90:10) selama 24 jam. Tujuan penjenuhan tersebut yaitu untuk memastikan chamber sudah dipenuhi oleh uap fase gerak. Setelah fase gerak tersebut mencapai jarak dari tempat penotolan, lalu keluarkan plat dan dikeringkan pada udara terbuka. Setelah plat kering lihat di bawah lampu UV dengan panjang gelombang $366 \mathrm{~nm}$ selama 1 menit, dan didapatkan bercak berwarna gelap. Bercak yang terdapat pada plat tersebut disemprot dengan pereaksi AgNO3 yang tujuannya supaya bercak tersebut terlihat lebih jelas dengan mata. Hasil bercak yang terdapat pada plat tersebut menunjukkan warna putih pada pembanding, kontrol, dan sampel dengan posisi bercak yang terbentuk sejajar menunjukkan adanya kandungan natrium siklamat pada sampel. Pada pengujian ini diperoleh 3 sampel berada pada range positif. ${ }^{14}$ 
Pada uji kuantitatif, pembuatan larutan uji fungsi penambahan $2,5 \mathrm{~mL}$ asam sulfat p.a adalah untuk mengasamkan sampel, kemudian penambahan $50 \mathrm{ml}$ etil asetat adalah untuk mengekstrak siklamat, penambahan $15 \mathrm{ml}$ air adalah untuk melarutkan dan mengekstrak siklamat, penambahan $\mathrm{NaOH}$ adalah untuk memberikan suasana basa pada siklamat, dan fungsi penambahan sikloheksan adalah untuk mengkestrak siklamat, dan fungsi penambahan larutan hipoklorit adalah untuk menarik air yang ada pada larutan. ${ }^{15}$

Batas maksimum penggunaan natrium siklamat pada minuman sirup menurut peraturan kepala badan pengawas obat dan makanan Republik Indonesia Nomor 4 tahun 2019 adalah $250 \mathrm{mg} / \mathrm{kg}$ (BPOM 2019). Adanya peraturan bahwa penggunaan natrium siklamat masih diperbolehkan serta kemudahan mendapatkannya dengan harga yang relatif lebih murah dibandingkan dengan dengan gula alami, hal tersebut menyebabkan produsen pangan dan minuman terdorong untuk menggunakan natrium siklamat sebagai pemanis buatan. ${ }^{16}$

Siklamat yang dikonsumsi dalam dosis yang berlebihan dapat menimbulkan banyak gangguan bagi kesehatan. Beberapa gangguan kesehatan tersebut antara lain seperti migrain dan sakit kepala, kehilangan daya ingat, bingung, insomnia, iritasi, asma, hipertensi, diare, sakit perut, alergi, impotensi dan gangguan seksual, serta kebotakan. Siklamat yang dikonsumsi dalam dosis yang berlebihan akan mengakibatkan kanker otak. ${ }^{17}$

Dari hasil pengujian dengan spektrofotometri diperoleh kadar tertinggi pada sampel E yaitu $25,53165 \mathrm{mg} / \mathrm{kg}$ dan masih sesuai dengan peraturan yang ditetapkan oleh BPOM tahun 2019 yaitu $250 \mathrm{mg} / \mathrm{kgBB}$.

\section{KESIMPULAN}

1. Seluruh sampel Sirup Tradisional Aceh yang dijual di Kota Lhokseumawe mengandung natrium siklamat sebagai pemanis buatan dengan kadar tertinggi $25,53165 \mathrm{mg} / \mathrm{kg}$.

2. Kadar natrium siklamat dalam Sirup Tradisional Aceh yang dijual di Kota Lhokseumawe masih sesuai dengan kadar yang ditetapkan BPOM RI tahun 2019.

\section{DAFTAR PUSTAKA}

1. Setiawan EA, Ibrahim MN, Wahab D. Analisis Kandungan Zat Pemanis Sakarin dan Siklamat pada Minuman yang Diperdagangkan di Sekolah Dasar di Kelurahan Wua-Wua Kota Kendari. Jurnal Sains dan Teknologi Pangan 2016. 1: 45-50.

2. Nadesul H. Membesarkan Bayi Jadi Anak Pintar. Jakarta: Gramedia, 2008. 
3. Suci EST. Gambaran Perilaku Jajan Murid Sekolah Dasar di Jakarta. Jurnal Psikobuana 2009. 1: 29.

4. Karunia FB. Kajian Penggunaan Zat Adiktif Makanan (Pemanis dan Pewarna) Pada Kudapan Bahan Pangan Lokal di Pasar Kota Semarang. Food Science and Culinary Education Journal 2013. 2.

5. Handayani T, Agustina A. Penetapan Kadar Pemanis Buatan (NaSiklamat) Pada Minuman Serbuk Instan Dengan Metode Alkalimetri. Jurnal Farmasi Sains dan Praktis 2015. I(1)

6. Utomo Y, Hidayat A, Dafif M, Safifa. Studi Histopatologi Hati Mencit (Mus musculus L) yang Diinduksi Pemanis Buatan. Jurnal MIPA 2012, 35:122-129.

7. Cahyadi W. Analisis \& Aspek Kesehatan Bahan Tambahan Pangan. Jakarta: Bumi Aksara, 2008

8. Devitria R, Sepriyani H. Identifikasi Natrium Siklamat pada Minuman Sirup yang Dijual di Lima SD Kecamatan Sukajadi Pekan Baru, Universitas Abdurrab Jurnal Analis Kesehatan Klinikal Sains 2018. 6.

9. Saparinto C, Hidayati D. Bahan Tambahan Pangan. Yogyakarta: Kanisius, 2010

10. Sudjadi. Kimia Farmasi Analisis, Yogyakarta: Pustaka Belajar, 2012.

11. Wahyuni. Identifikasi dan Penetapan Kadar Nipagin dalam Produk Shampo Secara Kromatografi Lapis Tipis dan Spektrofotometri. Surakarta: Karya Tulis Ilmiah Fakultas Farmasi Universitas Setia Budi Surakarta, 2008.

12. Khopkar SM, Saptoraharjo A, Nurhadi A. Konsep Dasar Kimia Analitik. Jakarta: UI Press, 1990.

13. Petrus AS. Analisis Kualitatif dan Kuantitatif pemanis buatan natrium siklamat pada minuman berenergi di Palangka Raya. Palangka Raya: FKIP UNIV Palangka Raya, 2013.

14. Skripsi Aprillia BA. Faktor yang Berhubungan dengan Pemilihan Makanan Jajanan pada Anak Sekolah Dasar (Skripsi). Semarang: Program Studi Ilmu Gizi Fakultas Kedokteran Universitas Diponogoro, 2011

15. Regina TP, Marwadi S. Validasi Metode Analisis Siklamat secara Spektrofotometri dan Turbidimetri. Jurnal Sains Dasar Univ Karangmalang Yogyakarta 2015. 4(1): 23-9.

16. Nurul Q, Karmila. Identifikasi Siklamat pada kuah dadar gulung yang dijual dikawasan pelabuhan Rambang kota Palangka Raya. Palangka Raya: Surya Med, 2017.

17. Depkes RI. Hati-hati Jangan Jajan Sembarangan, Diakses dari http://www.gizikia.depkes.go.id/archives/837, 2011. 